\title{
Silo 3 Vacuum Wand Demonstration Test FINAL REPORT
}

\section{U.S Department of Energy} Office of Science and Technology Technical Assistance to the Fernald Closure Project

\section{June 2003}

Idaho National Engineering and Environmental Laboratory Bechtel BWXT Idaho, LLC 
INEEL/EXT-03-00773

\title{
Silo 3 Vacuum Wand Demonstration Test
} FINAL REPORT

\author{
U.S. Department of Energy \\ Office of Science and Technology \\ Technical Assistance to the \\ Fernald Closure Project
}

June 2003

Idaho National Engineering and Environmental Laboratory

Idaho Falls, Idaho 83415

Prepared for the

U.S. Department of Energy

Assistant Secretary for Environmental Management

Under DOE Idaho Operations Office

Contract DE-AC07-99ID13727 


\section{EXECUTIVE SUMMARY}

Silo 3, a freestanding, pre-stressed concrete, domed cylindrical tank, located at the Fernald Closure Project near Cincinnati, Ohio, contains approximately 5,100 cubic yards of metal oxide waste generated from Fernald operations that extracted uranium from ore material. The baseline for the Silo 3 Project is to remove a portion of this material from the silo pneumatically by inserting vacuum retrieval wands and/or hoses in existing manways on the silo dome. After the loose material has been removed by the pneumatic system, the project intends to cut an opening in the silo wall and use a mechanical excavator to complete removal of the remaining material, including possible combination with pneumatic retrieval.

Fluor Fernald previously requested that the Department of Energy Environmental Management Office of Science and Technology provide a Technical Assistance Team to review this approach. One of the key recommendations made by this team was to assess the wand operability, effectiveness, reliability, and safety in a mock-up test.

A team was convened to develop the test plan, build the demonstration test loop, and perform the tests. The tests focused primarily on the operability of the system, and to a significantly lesser extent process performance. This report documents the results for the testing completed in April 2003. Based upon the testing performed, the team identified several key issues to be incorporated into the design and operation of the retrieval system. These issues are as follows:

- $\quad$ Performing the vacuum operation while standing on the sloped dome is tiring and difficult for the operators. A flat floor surface needs to be built around each Silo manway to be used for retrieval operations.

- Two operators are required to safely and effectively manage the vacuum wand system.

- The hoist used to support the hose and wand should be electrically controlled and the hose cradle should have a roller to facilitate hose travel.

- $\quad$ Bends create likely places for material to build up which can result in plugs. The final system needs to have minimal bends between the blower and the wand. Any necessary bends need to have as large a radius as feasible.

- A 4-inch vacuum wand system appears to be as large a system as can be physically managed for any length of time and should include an attachment to assist the operator in handling the wand.

- Being able to see into the manways and the use of a clear hose allows the operator to ensure adequate retrieval is occurring. Also, the use of a remote camera was demonstrated to be an effective operator aid.

- $\quad$ During retrieval significant ratholing occurred in the surrogate material due to its moisture content. This may or may not be an issue with Silo 3 material.

- Use of the 8-foot extension section welded to a 5-foot wand/nozzle enabled the greatest horizontal reach and was more effective in retrieval than using hose sections. 
- Proper airflow is critical to retrieval. A manual air bleed is required just upstream of the wand to enable the operator to effectively manage vacuum control.

- To maximize retrieval rate, the ability to retrieve from multiple manways in parallel is necessary.

Incorporating these elements into the design and operation of the pneumatic retrieval system will successfully enable retrieval of the waste material from the silo, at least to a depth that allows the removal of the material away from the silo wall to allow the opening to be cut for use of the excavator system. 


\section{CONTENTS}

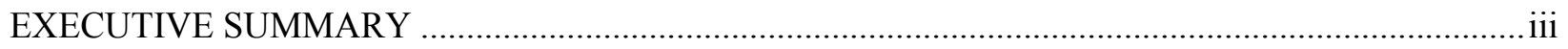

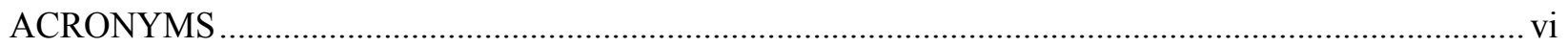

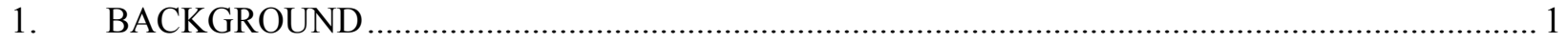

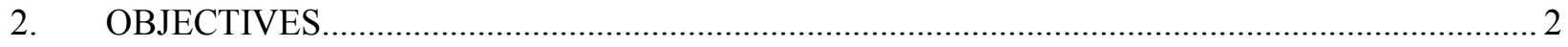

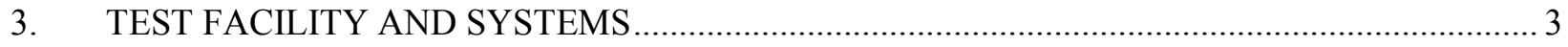

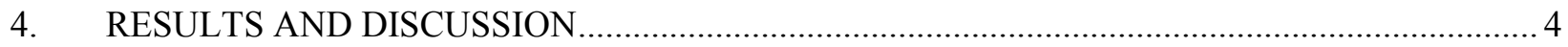

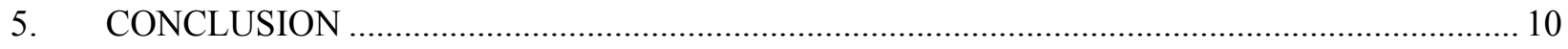

Appendix A-Silo 3 Vacuum Wand Demonstration Test Plan

Appendix B-Silo 3 Vacuum Wand Demonstration Test Data Sheets 


\section{ACRONYMS}

DOE Department of Energy

INEEL Idaho National Engineering and Environmental Laboratory

OST Office of Science and Technology

PPE Personal Protective Equipment

TAT Technical Assistance Team

VWMS Vacuum Wand Management System 


\section{Silo 3 Vacuum Wand Demonstration Test Final Report}

\section{BACKGROUND}

Silo 3 was constructed in 1952 as a freestanding, pre-stressed concrete, domed cylindrical tank. It is 80 feet in diameter and about 33 feet above ground level. The material in Silo 3 consists of approximately 5,100 cubic yards of metal oxide waste generated from Fernald operations that extracted uranium from ore material. The material has a dry bulk density of about 50 pounds/cubic foot. The predominant radionuclide of concern within the Silo 3 waste is thorium-230. The waste was pneumatically placed into the silo until 1957

Material characterization studies indicate that the upper two-thirds of the material in Silo 3 is dry and loose enough to be removed by pneumatic (vacuum) retrieval. The material in the bottom one-third of Silo 3 is thought to be in a hardened or compacted condition and may not be removed readily by the pneumatic system. The Silo 3 Project intends to initiate removal of material from the silo pneumatically by inserting vacuum retrieval wands and/or hoses in existing manways and ports on the silo dome. After the loose material has been removed by the pneumatic system, Fluor Fernald intends to cut an opening in the silo wall and use a mechanical excavator to complete the removal of the material, including possible combination with pneumatic retrieval.

Fluor Fernald previously requested that the Department of Energy (DOE) Environmental Management Office of Science and Technology (OST) provide a Technical Assistance Team (TAT) to:

- Independently review a design of the Silo 3 Vacuum Wand Management System (VWMS) with respect to constructability, operability, safety, performance, reliability and maintenance

- Recommend improvements to the current design and/or propose an alternate design

- $\quad$ Assist with scoping a prototype test of the VWMS.

The TAT concluded that the design of the VWMS would pneumatically retrieve Silo 3 waste. However, due to the limited range of motion associated with the wand design, the TAT also concluded that a significant quantity of loose material may not be readily retrievable. To address this and other identified issues; the TAT made several recommendations to enhance the wand operability, effectiveness, reliability and safety. Further assessment in a mock-up was recommended to determine which options are preferred and to assist in the actual final equipment design.

In line with these recommendations, Fluor Fernald established a team comprised of personnel from Fluor Fernald, the Hi-Vac Corporation, DeBra Kuempel, and the Idaho National Engineering and Environmental Laboratory (INEEL) to plan and perform the mock-up demonstration tests to evaluate equipment proposed for retrieval of the material from Silo 3.

A planning meeting was held at the Fernald site on February 13, 2003 to discuss the objectives of the mock-up tests, develop a preliminary list of test equipment, and to assign actions to facilitate initiation of the tests. Hi-Vac was assigned the action to finalize the list of test equipment. The list was developed and documented in a letter issued to Fluor Fernald on February 24, 2003. DeBra Kuempel was assigned the design and construction of the mock-up at their fabrication shop located in Cincinnati, Ohio. The INEEL was assigned the preparation of the Silo 3 Vacuum Wand Demonstration Test Plan (Appendix A). The plan, issued on April 16, 2003 as Fluor Fernald document \#40430-PL-0011 Rev. 0, outlined the test objectives, tests to be performed, and the team's roles and responsibilities. The INEEL was also assigned the primary responsibility for developing this final report. 


\section{OBJECTIVES}

The team and Silo 3 Project management reviewed the baseline design and the TAT recommendations to determine critical areas that needed evaluation during the mock-up testing. Based upon these evaluations the following set of objectives were established for the tests:

- $\quad$ Evaluate the range and range of motion of various wand/hose pieces

- $\quad$ Evaluate the ease of handling and maneuverability of various wand/hose pieces

- $\quad$ Evaluate operations ease with various lengths of wand/hose

- Evaluate effectiveness of varying diameters of wand/hose

- $\quad$ Evaluate effectiveness of various methods of flow and vacuum level controls

- Evaluate effectiveness of material retrieval from small 2-inch diameter ports

- Evaluate ease of changeout/addition of wand/hose sections

- $\quad$ Evaluate remote camera viewing

- $\quad$ Evaluate operations with operators in anticipated Personal Protective Equipment (PPE)

- $\quad$ Evaluate operator work platforms

- $\quad$ Identify safety and equipment damage hazards and associated mitigators

- $\quad$ Provide insight for final design of airborne contamination controls

- Evaluate wand/hose support hoist effectiveness and operational ease

- $\quad$ Provide insight to final design of hoist system

- Identify other elements of improvement for final VWMS design. 


\section{TEST FACILITY AND SYSTEMS}

The mock-up system was built to closely simulate the configuration of the Silo 3 dome. The floor was sloped at a pitch of $13^{\circ}$ and included one 20-inch manway sloped at $17^{\circ}$, one 24-inch manway sloped at $25^{\circ}$, and three 2-inch sounding ports. A rolloff vessel was beneath the test platform to contain the surrogate material for the retrieval tests. The slope of the floor resulted in the top of the surrogate material being approximately three feet below the 24-inch manway and six feet below the 20-inch manway. The material depth was approximately five feet.

A HiVac Model 475 portable vacuum loader with two 1-1/2 cubic yard rolloff vessels was used to provide the motive force for retrieval. A 50 -foot section of 6 -inch hose was connected to the vacuum loader. The 6-inch hose was connected to a 50 -foot section of 5 -inch hose, followed by a 50 -foot section of either 4-inch, 3-inch, or $1 \frac{1}{2}$-inch hose depending on the test being run. The vacuum wand and any extension sections were connected to the ends of these hoses and inserted into the rolloff vessel for the retrieval tests. The final hose section was supported by a hose cradle and a chain hoist that could be stationed over either manway to facilitate the handling of the vacuum wand system.

A diagram of the demonstration test system is presented in Figure 1.

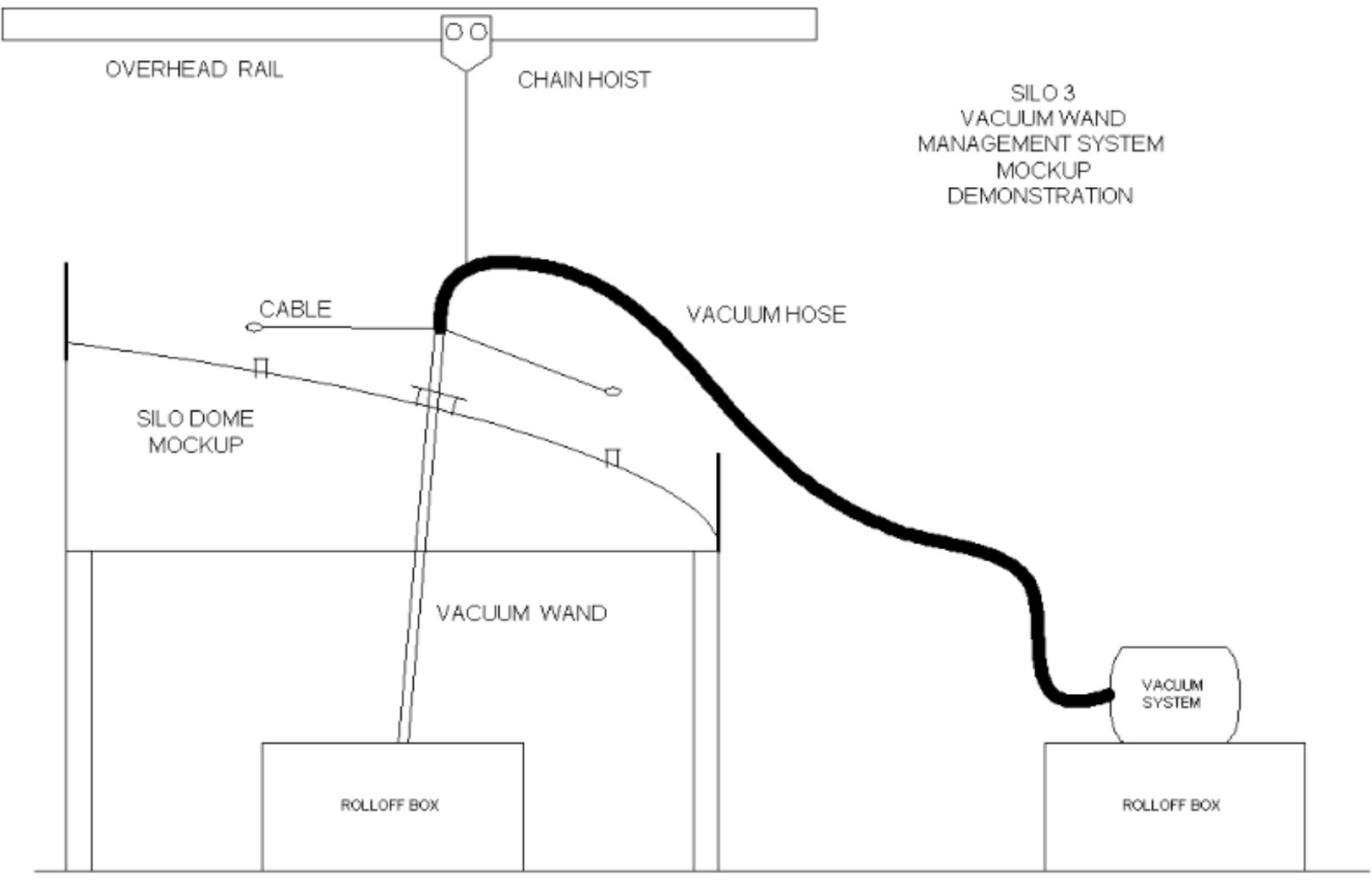

The test plan originally called out the use of fly ash as the surrogate material for the tests. However, environmental regulation hurdles arose during the procurement of this material so a shredded soil was used in its place. The soil appeared to be somewhat wet with a moisture content on the order of $20 \%$ compared to between $3-10 \%$ expected for the silo material. This is believed to be a worse case retrieval scenario as compared to what is expected in Silo 3. 


\section{RESULTS AND DISCUSSION}

The demonstration tests were conducted at the DeBra Kuempel fabrication shop from April 21-23, 2003. Personnel from Fluor Fernald, HiVac Corporation, Debra Kuempel, and the INEEL conducted the tests. The vacuum blower performed very well during the tests conducted with no operational issues identified.

The test plan originally called out 18 specific tests to be conducted. During final assembly of the test equipment it was identified that there was insufficient room on the dome mock-up to physically manage the 5 or 6 -inch hoses. Therefore tests with those specified hose sizes were eliminated. Additionally, during the second test, RTL-1-J, it was noted that the bulk nozzle (a nozzle with an air shroud) was much less efficient than the simple round nozzle in retrieval of the material. This type of nozzle allowed too much airflow via the ports on the side of the wand. Due to this, no further tests were conducted using bulk nozzles.

The following sections highlight the results of the tests per the objectives outlined in Section 2 . This information should be used to guide modifications for the final system design, to aid in the development of the operating procedures, and for operator training. The data sheets for the tests conducted are included as Appendix B.

Evaluate the range and range of motion of various wand/hose pieces

Various combinations of hoses, extension tubes, and wands were used during the tests. The greatest range was achieved using a combination of a 5-foot wand and an 8-foot extension tube. This enabled the operator to effectively reach a circular area of approximately eight feet in diameter. This combination was tested with the connection between the wand and extension tube made with a hose coupler and as a welded connection. It was determined that the welded connection was much more effective. The rigid connection allowed the operator to have better control of the location of the nozzle and therefore control of where retrieval is occurring.

Use of the 5-foot wand was also tested by just extending the hose down into the rolloff vessel. This setup was somewhat easier to manipulate compared to the extension tube approach in that the hose tends to travel somewhat on its own. The disadvantage of this setup was that it proved more difficult to control placement of the nozzle.

The final design should incorporate the ability to use both hoses and extension tubes. Camlock or similar type connections should be used for the tubing and wand connections to ensure the rigidity necessary for operator control of the nozzle placement.

Evaluate the ease of handling and maneuverability of various wand/hose pieces

Several key parameters were discovered during the tests conducted. In general, two operators are required to effectively manage the retrieval system. One operator is needed to manage the length of hose to the manway and to properly position the height of the hoist. This allows the second operator to focus their efforts on managing the wand to maintain optimal waste retrieval. The rigid system described in the preceding section allowed the operators to maintain more constant contact with the material, which resulted in higher retrieval efficiency. While the handling of the various systems tested proved to be satisfactory, the team believes that handling can be improved by the addition of a removable steering wheel device that can be connected to the hose or extension tube. HiVac has significant experience with this device and believes this will prove to be easier to use for the long hours of operation needed to retrieve the waste from the silo. 
Both 3-inch and 4-inch systems were satisfactorily tested during this activity. The 3-inch system proved to be somewhat easier to physically handle compared to the 4-inch system yet that resulted in a lower retrieval rate. Operations believe that a 4-inch system is as large a system as can be handled on an ongoing basis. The final design should incorporate the ability to use both the 3 and 4 -inch sizes.

\section{Evaluate operations ease with various lengths of wand/hose}

The longest system length tested was a 5-foot wand and 8 -foot extension tube for an overall length of 13 feet. The operators were able to effectively manage this system, shown here, and felt that an additional 8-foot extension system for an overall length of 21 feet could also be handled. The final design should incorporate the ability to use multiple lengths of extension tubes.

\section{Evaluate effectiveness of varying diameters of wand/hose}

Retrieval rates were determined for $1 \frac{1}{2}, 3$, and 4 -inch diameter hose/wand configurations. The $1 \frac{1}{2}$-inch system was ineffective for use in bulk retrieval. There was a significant tendency for plugs to occur in this smaller line and in the nozzle itself. Plugging also occurred in the $1 \frac{1}{2}$-inch hose splitter causing loss of vacuum. (The vendor believes that this could be overcome with a slightly different design.)

However, the $1 \frac{1}{2}$-inch system was found to be very effective in retrieval of small debris items. Enough vacuum was created in the smaller line such that the nozzle could be placed over the debris. The debris would stick to the nozzle and could be lifted out of the manway for removal.

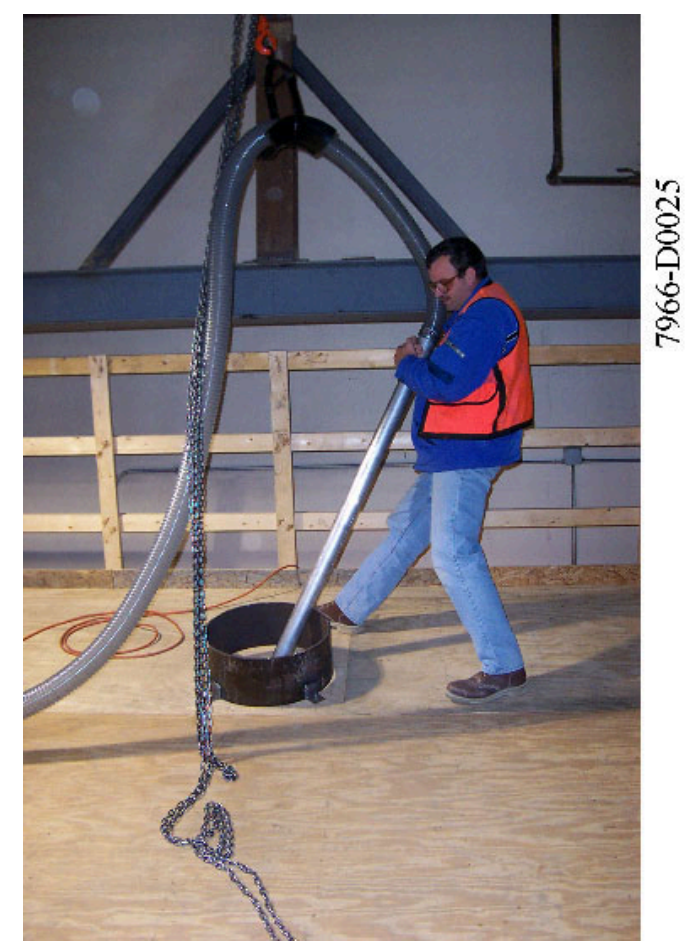

Retrieval rates for the 3 and 4-inch diameter systems were typically in the 2 cubic yard/hour range. The maximum retrieval rate seen occurred in run RTL-1-NNN. This run was conducted using a 5-foot by 4 -inch diameter wand welded to an 8-foot tubing extension. This system enabled the operator to maintain continual nozzle contact with the material and achieve a retrieval rate of approximately $4 \frac{1}{2}$ cubic yards/hour. Much of the difficulty in achieving more effective retrieval was the inability of the operator to control the airflow. A manually operated bleed valve should be installed above the wand/tubing section to allow the operator to effectively control retrieval.

Another factor that contributes to the retrieval rates is the flow properties of the material. As previously noted, the surrogate material used for the tests appeared to have a fairly high moisture content compared to that expected in the silo waste. The surrogate material could be readily compacted and did not flow well. During the test runs, the material exhibited a strong tendency to rathole as shown in the accompanying photograph. The material behaved such that a cave or tunnel could be dug back into the material without any collapse suggesting that this material had an angle of repose over $90^{\circ}$. The drier nature of the wastes expected to be encountered in the upper section of Silo 3 should result in higher retrieval rates than was experienced during the tests. 
Additionally, none of the configurations tested fully utilized the capacity of the vacuum blower. It is believed that the blower specified for the final design will easily be able to handle multiple 3 or 4 -inch systems operating simultaneously so that higher retrieval rates can be achieved. The use of air bleed valves and multiple systems should be designed into the final system. These improvements should enable operations to achieve the desired retrieval rates of 6-10 cubic yards/hour.

\section{Evaluate effectiveness of various methods of flow and vacuum level controls}

Several parameters were identified during

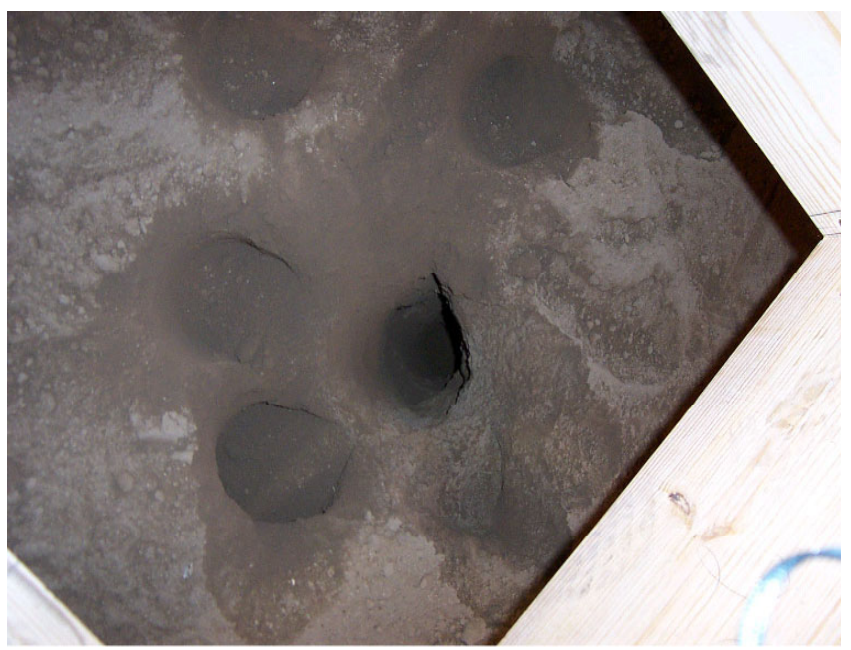

7966-D0013 the test runs that need to be incorporated into the final design. Round nozzles were found to by much more effective than bulk nozzles. The bulk nozzles allowed too much airflow resulting in minimal material retrieval. Additionally, as mentioned in the previous section, manual air bleed valves need to be installed in each system above the end of the wand/extension tube section to give the operator more control over the vacuum. It should be noted that vacuum control and corresponding retrieval efficiency improved throughout the tests as the operators became more proficient in handling the system. Experience gained in the initial operations at Silo 3 will aid the operators in achieving higher retrieval rates than will initially be obtained.

\section{Evaluate effectiveness of material retrieval from small 2-inch diameter ports}

As previously mentioned, material retrieval using the smaller size equipment was ineffective. There was a significant amount of plugging that occurred in the nozzle, hose, and manifold splitter with this size system. Additionally, there is no ability to maneuver the wand in the smaller port meaning that retrieval only occurs in a vertical manner. Unless the material in Silo 3 readily flows, retrieval using the small sounding ports is not expected to be of much value.

\section{Evaluate ease of changeout/addition of wand/hose sections}

Changing out the wands, hoses, and tubing sections was simple to perform. This operation could be manually performed with little downtime. However, trying to slide hoses over the wand and tubing sections is a bit hard to do and would be even tougher inside a radiological containment. Ensuring that the final design specifies camlock type fittings will enhance changes. Quick-disconnect fittings such as these should enable changes between wands, hoses, and tubing extensions to be easily made.

\section{Evaluate remote camera viewing}

The testing demonstrated that visually being able to monitor retrieval is very important in order to achieve the highest retrieval rates. The operators are able to quickly tell at a glance if vacuum control is adequate, if plugs are occurring, or if material flow is sufficient. Clearly, the most effective means to do this is to ensure that the operators have direct visual access to the manhole being used for waste retrieval. If this is not allowable from a radiological safety perspective then the use of cameras can be implemented. Remote camera (bullet camera/BT 704W) viewing was conducted during the test runs using three different scenarios as discussed below. 
A camera was installed in one manhole while retrieval occurred in the other. In this arrangement, the operator was able to see where the nozzle was located and whether or not waste was being retrieved. Positioning of the viewing screen is important to ensure that the operator can view the screen while maintaining control of the vacuum wand.

The second setup was to place the camera into the same manhole the waste was being retrieved from. This arrangement was a little more effective for the operators in that they could directly view the operation and could guide better placement of the nozzle. The disadvantage of the first two scenarios was that it required a third operator to handle the camera system.

The third setup was to mount the camera onto the vacuum wand for placement into the manhole during retrieval operations. The camera was mounted to the wand approximately three feet above the nozzle. This allowed improved functionality over the second scenario. Retrieval operations were easier to maintain while also having the advantage that this setup did not require a third operator. This setup was the preferred arrangement of the three. The only drawback to this setup is that the operator must use caution when maneuvering the wand to ensure that the camera is not jarred against the side of the manhole causing damage to the camera.

\section{Evaluate operations with operators in anticipated Personal Protective Equipment (PPE)}

Operators wearing safety glasses and shoes conducted the test runs. No other PPE, such as anticontamination clothing or respirators was worn during the tests. Operations believe that the system can be adequately managed even in full PPE. The only potential issue of concern is that of temperature. In that this is a labor-intensive operation, some mechanism to keep operators cool during warmer days may be necessary to ensure those operators can work for extended periods of time.

\section{Evaluate operator work platforms}

The test system floor was built at a $13^{\circ}$ slope to approximate an "average slope" of the silo dome. Management of the wand system on a floor of this slope for the duration of the test runs, the longest continuos test ran approximately 30 minutes, was somewhat tiring. Due to the extended time frames that the operators will be managing retrieval operations it is recommended that level platforms be built around the manways. This will be especially critical for the manways located on the steeper slope encountered around the outer portions of the dome.

\section{$\underline{\text { Identify safety and equipment damage hazards and associated mitigators }}$}

Several potential hazards were identified during the tests. As discussed above, the operators need to be provided with a stable, level platform. The platform and containment structure must be as large as possible to enable the operators to be able to maneuver within the containment structure and to be able to add or remove hose/tubing sections. At a minimum it is recommended that the platforms be 30 feet square with 15 feet of clearance above the manway. Fall protection also needs to be considered in the final design.

If a remote camera connected to the vacuum wand is used, the design should include a mechanism to firmly attach the camera to the wand. The mechanism should also be designed to allow for quick camera removal and the camera should be provided with some type of protective padding.

In the later stages of the testing, Fluor Fernald safety personnel witnessed the testing and were briefed on the overall system. The test team discussed the optimal situation being that the operators are able to see directly into the manhole during retrieval operations. The team feels that this is a safe 
situation for these operations. If it is determined that a bag type housing must be place around the manhole during operations to provide an improved safety margin, it can be expected that retrieval rates will drop.

\section{$\underline{\text { Provide insight for final design of airborne contamination controls }}$}

Contamination control aspects were not evaluated during the initial testing; however, ongoing evaluations are being conducted to support the final design.

\section{$\underline{\text { Evaluate wand/hose support hoist effectiveness and operational ease }}$}

Use of the hoist was deemed to be critical to successful operations. The hoist holds most of the weight and allows the operator to focus more on correct positioning of the nozzle for optimal retrieval. Electric hoists should be provided at each retrieval location during retrieval operations.

\section{Provide insight to final design of hoist system}

Several key features were identified during the tests that should be incorporated into the final system design. First, the hoist should be positioned a minimum of 15 feet in height above the top of the manway. This will ensure that the operators have sufficient headroom to add/remove extension tubes and to manipulate the system during retrieval. Secondly, the hoist should be provided with electric operation for vertical travel adjustments. The manual operation of the hoist in the test system proved burdensome and inefficient. Lastly, the hoist cradle needs to have a roller system to allow for easy hose travel. The easier one operator can feed hose in and out the easier it is for the second operator to maintain nozzle contact with the waste.

\section{Identify other elements of improvements for final VWMS design} as follows.

As a result of the testing, the team was able to develop several additional design recommendations

To ensure that the retrieval rates are kept to an acceptable level, it is paramount that downtime of the vacuum system be minimized. In that regards the final design needs to ensure that the number of bends in the piping and/or hose runs be kept to a minimum. Significant material buildup at bends was prevalent throughout the testing. Any bends that must be used should be of as large a radius as practical. The team also recommends that clear hose be used all the way from the retrieval end to the vacuum blower. Using clear hose rather than piping offers several significant advantages. The easiest way for the operator to ensure that line plugs do not occur is to be able to visually see into the transfer line to monitor operations. In the event that plugs do occur, being able to see into the system also allows for expedient line clearing.

As discussed in a previous section, significant ratholing was observed during the testing. Much of this is attributed to the surrogate material used during the tests and this is expected to be less of an issue during operations. However, the potential still exists that the silo waste material may not always flow adequately to enable effective retrieval. Some type of mechanical activation device(s) should be considered for the system to be able to break up any material peaks that form.

Lastly, the blower specified by HiVac for the final system is a 150 horsepower vacuum blower. This blower should be capable of handling at least two 3 or 4-inch wands operating in parallel. Having the ability to operate multiple systems at once is an important feature to incorporate into the final design to ensure that adequate retrieval rates are achieved. 


\section{CONCLUSION}

The primary objective of the test was to ensure that the key parameters were identified for incorporation into the final design to ensure successful retrieval of the waste from Silo 3 . The tests demonstrated that the VWMS should be effective in waste retrieval at least to a sufficient depth to enable installation of the mechanical excavator and potentially for full retrieval. Inclusion of the items identified in the previous section in the final design of the VWMS should enable Fluor Fernald to meet the Silo 3 Project schedule. 


\section{Appendix A \\ Silo 3 Vacuum Wand Demonstration Test Plan}




\section{Silo 3 Vacuum Wand Demonstration Test Plan 40430-PL-0011 Rev. 0}

Approvals:

Mike Griffin

Project Engineer

Signature

Date

Doris Edwards

Project Manager

Signature

Date

\section{Concurrence:}

Tim Huey

Operations

Signature

Date 


\section{Table of Contents}

$\begin{array}{lll}1.0 & \text { Introduction } & 3\end{array}$

$\begin{array}{lll}2.0 & \text { Background } & 3\end{array}$

3.0 Objectives 4

4.0 Designation of Core Team and Key Responsibilities 4

5.0 Test Facility and Systems 5

5.1 Vacuum Wand and Hose Selection 5

5.2 Retrieval Test Loop 5

5.3 Test Facility 6

$\begin{array}{lll}5.4 & \text { Surrogate Material } & 7\end{array}$

$\begin{array}{lll}6.0 & \text { Retrieval Test Loop Runs } & 7\end{array}$

6.1 RTL Series 1 Runs $\quad 7$

6.2 RTL Series 2 Runs 8

$\begin{array}{lll}\text { 7.0 Test Run Evaluations and Final Test Report } & 9\end{array}$

$\begin{array}{llr}8.0 & \text { References } & 9\end{array}$

$\begin{array}{ll}\text { Appendix } & 10\end{array}$ 


\subsection{Introduction}

This test plan describes the objectives and plans for performing a mock-up demonstration test of various types and sizes of vacuum wands, hoses, and accessories proposed for pneumatic retrieval of waste material from Silo 3 at the Fernald Closure Project (FCP).

\subsection{Background}

Silo 3 was constructed in 1952 as a freestanding, pre-stressed concrete, domed cylindrical tank. It is 80 feet in diameter and about 33 feet above ground level. The material in Silo 3 consists of approximately 5,100 cubic yards of metal oxide waste generated from Fernald operations that extracted uranium from ore material. The material has a dry bulk density of about $50 \mathrm{lb} / \mathrm{ft}^{3}$. The predominant radionuclide of concern within the Silo 3 waste is thorium-230. The waste was pneumatically placed into the silo until 1957

Material characterization studies indicate that the upper two-thirds of the material in Silo 3 is dry and loose enough to be removed by pneumatic (vacuum) retrieval. The material in the bottom one-third of Silo 3 is thought to be in a hardened or compacted condition and may not be removed readily by the pneumatic system. The Silo 3 Project intends to initiate removal of material from the silo pneumatically by inserting vacuum retrieval wands and/or hoses in existing manways and ports on the silo dome. After the loose material has been removed by the pneumatic system, Fluor Fernald intends to cut an opening in the silo wall and use a mechanical excavator to complete the removal of the material, including possible combination with pneumatic retrieval.

Fluor Fernald previously requested that the DOE Environmental Management Office of Science and Technology (OST) provide a Technical Assistance Team (TAT) to:

- Independently review a design of the Silo 3 Vacuum Wand Management System (VWMS) with respect to constructability, operability, safety, performance, reliability and maintenance;

- Recommend improvements to the current design and/or propose an alternate design;

- Assist with scoping a prototype test of the VWMS.

The TAT concluded that the design of the VWMS would pneumatically retrieve Silo 3 waste. However, due to the limited range of motion associated with the wand design, the TAT also concluded that a significant quantity of loose material may not be readily retrievable. To address this and other identified issues; the TAT made several recommendations (Reference 1) to enhance the wand operability, effectiveness, reliability and safety. Further assessment in a mock-up was recommended to determine which options are preferred and to assist in the actual final equipment design.

In line with these recommendations, Fluor Fernald has procured a contractor (Hi-Vac Corporation, with Mole-Master Services Corporation partnership), with significant experience in vacuum and silo cleanout technology, to assist in planning and performance of a mock-up demonstration test to evaluate equipment proposed for retrieval of the material from Silo 3. 


\subsection{Objectives}

Following are objectives of the demonstration testing, regarding material retrieval trials, with the various wand and hose pieces of equipment, from silo dome manways and ports:

a. Evaluate the range and range of motion of various wand/hose pieces,

b. Evaluate the ease of handling and maneuverability of various wand/hose pieces,

c. Evaluate operations ease with various lengths of wand/hose,

d. Evaluate effectiveness of varying diameters of wand/hose,

e. Evaluate effectiveness of various methods of flow and vacuum level controls,

f. Evaluate effectiveness of material retrieval from small 2-inch diameter ports,

g. Evaluate ease of changeout/addition of wand/hose sections,

h. Evaluate remote cameral viewing,

i. Evaluate operations with operators in anticipated Personal Protective Equipment (PPE),

j. Evaluate operator work platforms,

k. Identify safety and equipment damage hazards and associated mitigators,

1. Provide insight for final design of airborne contamination controls,

m. Evaluate wand/hose support hoist effectiveness and operational ease,

n. Provide insight to final design of hoist system,

o. Identify other elements of improvement for final VWMS design.

\subsection{Designation of Core Team and Key Responsibilities}

In order to ensure a successful demonstration for the Silo 3 Project in a reasonable time line that supports the current project schedule, a core team from private industry (Hi-Vac) and DOE contractors has been assembled to plan and conduct the demonstration. Overall responsibility and project oversight, as well as test operation, is provided by Fluor-Fernald; the Hi-Vac Corporation is responsible for vacuum wand management system component selection with input from all core team members and assistance in test operation; the Idaho National Engineering and Environmental Laboratory (INEEL) is responsible for preparation of the test plan with input from the core team and technical support; and DeBra- Kuempel (general construction contractor) is responsible for mock-up design and construction. Since much of the equipment evaluation will be subjective and based on visual and physical observations, it is important to have these multiple organizations involved in the evaluation and reporting. INEEL will be involved in test evaluation and final report preparation, along with Fluor Fernald and HiVac. Fluor Fernald will be responsible for publication and distribution of the final report. The key activities and associated responsible personnel are summarized in Table 1. 
Table 1. Designation of responsibilities for Vacuum Wand Demonstration Test Team

\begin{tabular}{|c|c|c|}
\hline Activity & $\begin{array}{c}\text { Responsible } \\
\text { Organization }\end{array}$ & $\begin{array}{c}\text { Responsible } \\
\text { Personnel }\end{array}$ \\
\hline Project Oversight & Fluor-Fernald & $\begin{array}{c}\text { Doris Edwards } \\
\text { Mike Griffin } \\
\text { Tim Huey }\end{array}$ \\
\hline Equipment Selection & Hi-Vac & Shawn Doolittle \\
\hline Test Plan Preparation & INEEL & Steve Birrer \\
\hline Mock-up Design and Fabrication & DeBra Kuempel & Ed Gettler \\
\hline Surrogate Specification & Fluor Fernald & Mike Griffin \\
\hline Test System Operation & Fluor Fernald & Tim Huey \\
\hline Test System Data Collection & Fluor Fernald & Tim Huey \\
& INEEL & Steve Birrer \\
\hline Data Evaluation & Fluor Fernald & Mike Griffin/Tim Huey \\
& INEEL & Steve Birrer \\
& Hi-Vac & Shawn Doolittle/Pat Snyder \\
\hline Report Preparation & INEEL & Steve Birrer \\
& Hi-Vac & Shawn Doolittle \\
\hline Report Publication & Fluor Fernald & Mike Griffin \\
\hline
\end{tabular}

\subsection{Test Facility and Systems}

\subsection{Vacuum Wand and Hose Selection}

Based upon a mock-up planning meeting, the Hi-Vac Corporation recommended the list of equipment (Reference 2) that should be tested to reliably demonstrate that the equipment is manageable by the operator and able to perform the material retrieval.

The equipment includes aluminum tubing of various sizes ( $1.5-6$ inches diameter) and lengths, wire reinforced hoses of various diameters and lengths, and wand/hose end attachments (nozzles) of various size, length, and design.

\subsection{Retrieval Test Loop}

Test runs to be conducted in the Retrieval Test Loop (RTL) and the objectives for those tests are presented in Section 6 of this Test Plan. A brief description of the RTL and the general objectives of this system are included in this section.

The surrogate material (fly ash), which physically simulates the contents of Silo 3, will be placed in a rolloff box. The material depth will be $\sim 5 \mathrm{ft}$ to simulate the waste in the top portion of the Silo. A mock-up of the silo dome will be fabricated on a $17^{\circ}$ pitch and includes two large manways and two or more 2 -inch sounding ports to approximate a typical section of the dome used for actual waste retrieval. The dome mock-up is built into a platform over the surrogate material tank to closely simulate the actual silo configuration. Initial testing will be performed with the dome mock-up placed on the top of the fly ash container to simulate material retrieval 
with the material near the manway using short wand/hose sections. Further testing will be performed with an elevated dome mock-up to evaluate the operation of longer wand/hose sections. The vacuum wand, nozzles, and hoses are full scale and identical to those planned for Silo 3 waste retrieval operations. A trolley with a chain hoist on a beam will be provided by DeBra-Kuempel to support and assist in movement of the vacuum wand and hoses.

The surrogate material will be vacuumed from the surrogate material tank using various combinations of wands, nozzles, and hose lengths. A portable vacuum loader (Hi-Vac Model 475 ; operating instructions will be provided by $\mathrm{Hi}-\mathrm{Vac}$ ) will be used to provide the vacuum. When the vacuum loader is full of material, operations will be halted and the material transferred from the vacuum loader back into the rolloff box.

\subsection{Test Facility}

The RTL will be assembled and tested in the DeBra-Kuempel fabrication shop located in Cincinnati, Ohio. A diagram of the demonstration test setup is presented in Figure 1.

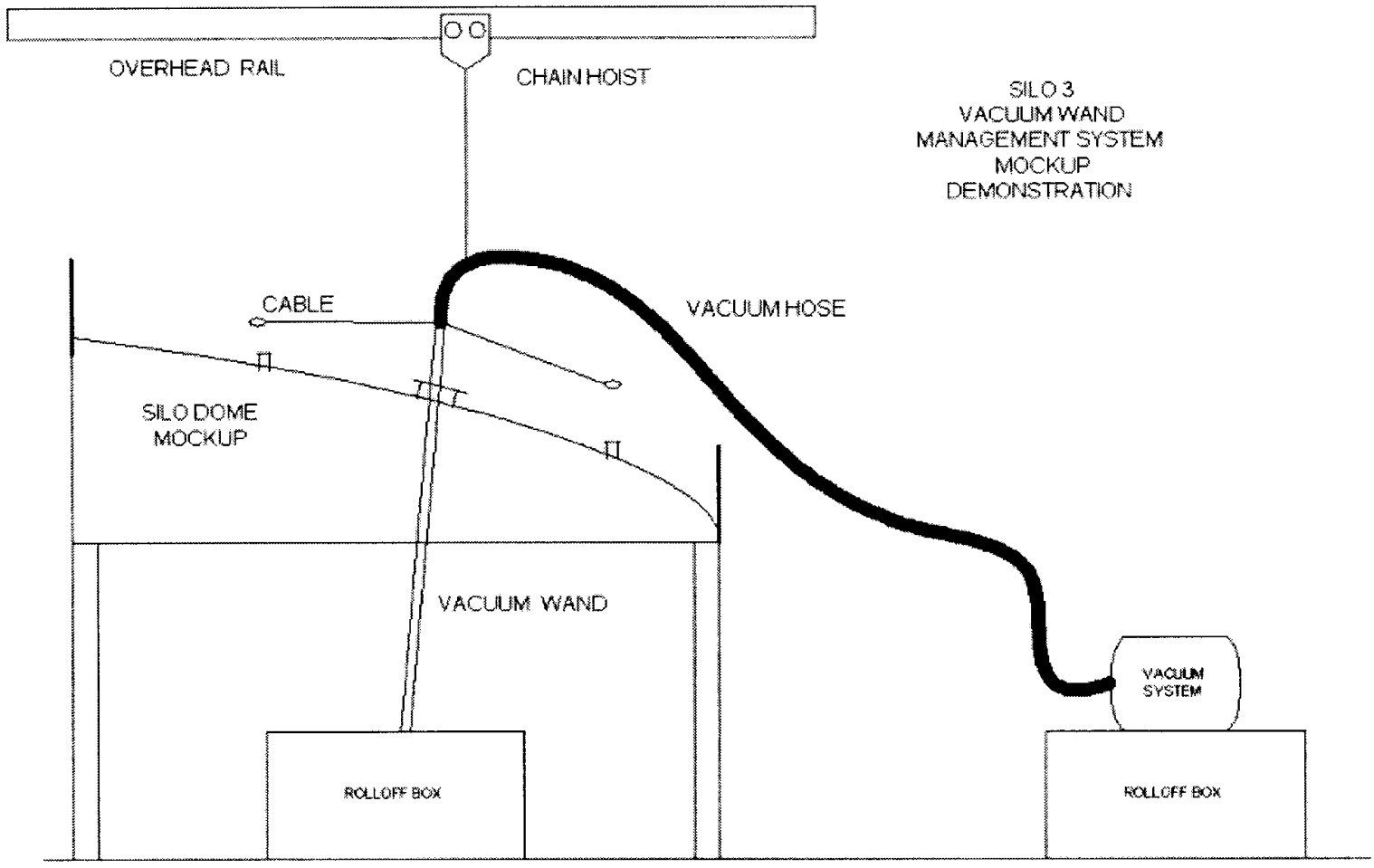

Figure 1. Silo 3 Vacuum Wand Management System Mock-up Demonstration 


\subsection{Surrogate Material}

The waste in the Silo 3 is a calcine residue generated from Fernald Environmental Management Project operations that extracted uranium from ore material. The residues consist of nitrate and sulfate salts of sodium, potassium, magnesium, and calcium, in addition to diatomaceous earth. The residues exist in a dry powdery state and have a density of 29 to 58 pounds per cubic foot. Characterization studies of the Silo 3 material were previously performed and documented (Reference 3).

Based upon this information, it was determined to use fly ash as the surrogate material for the testing. Given that the purpose of the tests is focused on equipment maneuverability, the surrogate material needs only to approximate the general physical properties of the actual silo waste material.

\subsection{Retrieval Test Loop Runs}

The RTL has been designed to simulate, at near full scale, the vacuum wand management system which will be utilized in Silo 3 at Fernald. A series of test runs will be conducted to demonstrate the operation the vacuum wand management system and its ability to retrieve waste from the top portion of the silo. The tests are scheduled to be conducted during the period of April 21-25, 2003. The following three sections describe the tests anticipated to be performed.

Note that modifications may be made to the tests, based upon initial results. Tests may be added, deleted, or modified to ensure the necessary objectives for the project are achieved.

\subsection{RTL Series 1 Runs}

The primary objectives of the RTL Series 1 runs are to determine the equipment configurations that are effective in retrieving the surrogate material from the manway and physically manageable from an operator's perspective. Test runs will be conducted as shown in Table 2 . During one or more of these runs a flexible boot or bag containment will be installed around the wand and hose sections to simulate the radiological containment required during actual operations. Additionally, during one or more tests, the operator will be wearing PPE (full-face respirator, gloves, anti-c clothing, etc. as specified by the safety engineer to simulate PPE that will be worn during actual operations). 
Table 2. RTL Series 1 Runs

\begin{tabular}{|c|c|c|c|}
\hline Run Designation & Vacuum Wand (in.) & Hose Size (in) & Nozzle Type \\
\hline RTL-1-A & 3 & 3 & Bulk \\
\hline RTL-1-B & 3 & 4 & Bulk \\
\hline RTL-1-C & 3 & 5 & Bulk \\
\hline RTL-1-D & 3 & 6 & Bulk \\
\hline RTL-1-E & 3 & 3 & Round Lance \\
\hline RTL-1-F & 3 & 4 & Round Lance \\
\hline RTL-1-G & 3 & 5 & Round Lance \\
\hline RTL-1-H & 3 & 6 & Round Lance \\
\hline RTL-1-I & 4 & 3 & Bulk \\
\hline RTL-1-J & 4 & 4 & Bulk \\
\hline RTL-1-K & 4 & 5 & Bulk \\
\hline RTL-1-L & 4 & 6 & Bulk \\
\hline RTL-1-M & 4 & 3 & Round Lance \\
\hline RTL-1-N & 4 & 4 & Round Lance \\
\hline RTL-1-O & 4 & 5 & Round Lance \\
\hline RTL-1-P & 4 & 6 & Round Lance \\
\hline
\end{tabular}

The following information will be provided for each of these runs:

- Equipment tested

- Duration of the run (defined as the time from start to finish of the retrieval operation; does not include time to refill the rolloff box)

- Observations of the physical handling of the equipment

- Visual observations of the retrieval efficiency

- Observations relevant to objectives listed in Section 3.0.

- Videos will be taken for a portion of the runs

A sample data log sheet is included in Appendix 1.

\subsection{RTL Series 2 Runs}

The primary objectives of the RTL Series 2 runs are to determine the equipment configurations that are effective in retrieving the surrogate material from the sounding port and physically manageable from an operator's perspective. Test runs will be conducted as shown in Table 3 .

\section{Table 3. RTL Series 2 Runs}

\begin{tabular}{|c|c|c|c|}
\hline Run Designation & Vacuum Wand (in.) & Hose Size (in) & Nozzle Type \\
\hline RTL-2-A & $11 / 2$ & $11 / 2$ & Bulk \\
\hline RTL-2-B & $11 / 2$ & $11 / 2$ & Round Lance \\
\hline
\end{tabular}


The following information will be provided for each of these runs:

- Equipment tested

- Duration of the run

- Observations of the physical handling of the equipment

- Visual observations of the retrieval efficiency

- Observations relevant to objectives listed in Section 3.0.

- Videos will be taken for these runs

A sample data log sheet is included in Appendix 1.

\subsection{Test Run Evaluations and Final Test Report}

A debriefing will be conducted at the completion of each test run to discuss and evaluate the particular test. The discussion will be documented in the observation sections on the data log sheet.

After the tests have been completed, a final test report will be prepared which will discuss the overall results and observations from the tests. The final test report will address the test objectives and recommendations for final VWMS design.

\subsection{References}

1. Final Report - An Evaluation of the Vacuum Wand Management System for Silo 3 Waste Retrieval, dated November 6, 2002

2. Letter, Shawn Doolittle (Hi-Vac) to Mike Griffin (Fluor Fernald), Silo 3 VWMS Demonstration, dated February 24, 2003.

3. Silo 3 Design Data Development Report, Document No. 40430-RP-0015, Rev. 0, dated August 15, 2002. 


\section{Appendix}

\section{Data Log for RTL Tests}


Silo 3 Vacuum Wand Demonstration Test Data Sheet $\quad$ Page 1 of

Run No.:

Run Date:

Time Run Initiated:

Time Run Completed:

Equipment Tested:

Vacuum Wand:

Hose Size:

Nozzle Type:

Dome Height above Surrogate: Flexible Containment Bag Used: Yes / No

Other:

Observations:

Range/Range of Motion:

Ease of Handling/Maneuverabililty:

Retrieval efficiency:

Flow/Vacuum Control:

Ease of section changeout/addition:

Hoist operation:

Camera viewing:

Safety:

Working Platform:

Containment:

Other:

Operator:

Observers: 
Page _ of _ _

Other Notes / Observations:

Operator:

Observers: 


\section{Appendix B Silo 3 Vacuum Wand Demonstration Test Data Sheets}




\section{Silo 3 Vacuum Wand Demonstration Test Data Sheet}

\section{Page 1 of 1}

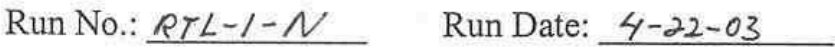

Time Run Initiated: $8: 29$ Time Run Completed: $8: 49$

Equipment Tested:

Vacuum Wand: $44^{\prime \prime} \times 3 f_{+}$Hose Size: $4^{\prime \prime}\left(50 f_{t}\right)$ Nozzle Type: Round

Dome Height above Surrogate: $3 \mathrm{ft}$ Flexible Containment Bag Used: Yes / $\mathbb{N o}$

Other: $24^{\prime \prime}$ manway

Observations:

Range/Range of Motion: Accertable

Ease of Handling/Maneuverabililty: Pcrrieval with minimal amerus of wort

Retrieval efficiency: Retricual at a fairlygood catej $\approx 2$ cuyd/hr

Flow/Vacuum Control: 10 in vacuem

Ease of section changeout/addition: NA

Hoist operation: See RTL-1-J

Camera viewing: Acceptab/e

Safety: Acceptable

Working Platform: Acceptable other than hord to stand on slope

Containment: Niced to be able to sec the hose

Other: Ensure clear hose is used so operator can tracts material flow. Able to dig a cave sideways with no collapse All participants operated the hose

Operator: Pat Snyder

Observers: Steve Birrev $\frac{\text { Tim Huey Shown Doolittle }}{\text { Mike Griffin }}$ 


\section{Silo 3 Vacuum Wand Demonstration Test Data Sheet}

\section{Page 1 of 1}

Run No.: RTL-1-J Run Date: $4-22-03$

Time Run Initiated: 7:58 Time Run Completed: $\underline{8: 20}$

Equipment Tested:

Vacuum Wand: 4 " $43 \mathrm{ft}$ Hose Size: 4 " $(50 \mathrm{ft})$ Nozzle Type: Bu/k

Dome Height above Surrogate: $6 \mathrm{ft}$ Flexible Containment Bag Used: Yes /No

Other: $20 "$ manway

Observations:

Range/Range of Motion: Accep ta ble

Ease of Handling/Maneuverabililty: Fair amoun of work to enable revricual

Retrieval efficiency: Very slow; too much air flow with this nozzlc xypelsize

Flow/Vacuum Control: On , 9 in vacuum ( $/ 8$ in vacuum capacing)

Ease of section changeout/addition: NA

Hoist operation: Need an elcetric hoist; quicker response than with chain pull

Camera viewing: Acceptable; Can be used to guide operations

Safety: Contaimment is going to bo diffiev/t. Moy need tent enclusure.

Working Platform: Accep table other whan hard to stand on slopej need tevel plar form

Containment: See safery

Other: Material readily builds up peates. Appears that it has a angle of repose of at least 90. Nozzle able to go straight fown with almost no material collapse.

Operator: Pat Snyder

Observers: $\frac{\text { Steve Birrer }}{\text { Mite Griffin }} \frac{\text { Tim Huey }}{\text { Nat Politi }}$ Shown Doolittle 


\section{Silo 3 Vacuum Wand Demonstration Test Data Sheet}

\section{Page 1 of 1}

Run No.: RTL-1-E Run Date: $4-22-03$

Time Run Initiated: $9: 30$ Time Run Completed: 10:05

Equipment Tested:

Vacuum Wand: 3 "*3ft Hose Size: 3 " $30 \mathrm{ft})$ Nozzle Type: Round

Dome Height above Surrogate: $3 \mathrm{ft}$ Flexible Containment Bag Used: Yes $₫$

Other: 24 "manway

Observations:

Range/Range of Motion: Easier to get horizontal travel into material

Ease of Handling/Maneuverabililty: Easier to use than 4" hose

Retrieval efficiency: Similar to previous test $\infty 2 \mathrm{cu}$ yd/hr

Flow/Vacuum Control: 14-18 in vaequm; Bmater relcases - can probably use $2-3^{\prime \prime}$ serups

Ease of section changeout/addition: $1 / A$

Hoist operation: Same as first test

Camera viewing: Able to see from manway to mancury $(10 \mathrm{ft})$ but comera closer

Safety: No issues (other than those already ideurified]

Working Platform: No issues beyand slope.

Containment: No additienal issues

Other: Two operators are necessary to effectirly move and manage the hose and nozzle. Building up a fair amount of material in 6" hose section.

Operator: Tim Heey

Observers: Steve Birrer $\frac{\text { Shawn Doolittle Pat Snyder }}{\text { Nat Polite }}$ 


\section{Silo 3 Vacuum Wand Demonstration Test Data Sheet

Run No.: RTL-/-EE Run Date: $4-22-03$

Time Run Initiated: /1 :50 Time Run Completed: 12:20

Equipment Tested:

Vacuum Wand: $3^{\prime \prime} \times 5 f \quad$ Hose Size: $3^{\prime \prime} \quad$ Nozzle Type: 3 "round

Dome Height above Surrogate: $3 f \pm, 6 f t$ Flexible Containment Bag Used: Yes No

Other: $\frac{8 f+\text { tube extensionj used both manways }}{\text { coupled by hose }}$

Observations:

Range/Range of Motion: less horicontal travel due to tube extension

Ease of Handling/Maneuverabilitty: heovier due to tubejmater it more difficult than host

Retrieval efficiency: Similor to test RTL-LE

Flow/Vacuum Control: Adequate vacuum; no breater relief

Ease of section changeout/addition: $\mathbf{N A}$

Hoist operation: Same as other tests

Camera viewing: Connecred camera to $5 \mathrm{ft}$ wand $\sim 4 \mathrm{ft}$ from tip

Safety: Same as other tests

Working Platform: Same as orther tests

Containment:Same as other tests

Other: As with other tests material yends to cathole significantly. May need to haue some noxive force lair jet, vibration to move
material even if its driev andmorc free flowing than surregate

Operator: Tim Huey

Observers: Steve Birrer $\frac{\text { Shawn Doulittle }}{\text { Nat Politi }}$ 
Silo 3 Vacuum Wand Demonstration Test Data Sheet

Page 1 of 2

Run No.: RTL-2-B Run Date: $4-22-03$

Time Run Initiated: 2:0S Time Run Completed: $2: 35$

Equipment Tested:

Vacuum Wand: 5 ff, 11/2" Hose Size: 11/2" Nozzle Type: Round

Dome Height above Surrogate: $3 \mathrm{fr}$ Flexible Containment Bag Used: Yes 1 No

Other: Used 3 muzzles at once ( 2 in 24 "manwayj / in 2"pon)

Observations:

Range/Range of Motion: OK j may be improved with tubing section added

Ease of Handling/Maneuverabililty: Easy to handle due to less wig ht

Retrieval efficiency: Tendance for 1'/2" lines to plug j nozzles alsoplug.

Flow/Vacuum Control: 12-18 in vacuum; vacuum relief breaker tincting in

Ease of section changeout/addition: NA

Hoist operation: Not used

Camera viewing: Down 24" manway

Safety: No new issues

Working Platform: No new issues

Containment: No new issues

other: Put debris (severalpiecess of cardboard plastic bag, and glue into surrogate pile. Easily retrieved by the $11^{\prime} 2$ "wand

Operator: Tim Huey

observers: Steve Diver Shawn Dovit/e Pat Snyder

28 


$$
R T L-2-B
$$

\section{Silo 3 Vacuum Wand Demonstration Test Data Sheet \\ Page $\underline{2}$ of $\underline{2}$}

Other Notes / Observations:

- Added Bft wubing section to end of nozzle. Able to provide alixte more horizontal reach. Coupled by hose.

- Significant plug build-up in 1/2 "splitter

Operator:

Observers: 


\section{Silo 3 Vacuum Wand Demonstration Test Data Sheet}

\section{Page 1 of $\underline{2}$}

Run No.: RTL-1-EEE Run Date: $4-23-03$

Time Run Initiated: 8:40 Time Run Completed: 9:10

Equipment Tested:

Vacuum Wand: $3^{\prime \prime} \times / 3 \mathrm{ft}$ Hose Size: $3^{\prime \prime}$ Nozzle Type: Round

Dome Height above Surrogate: $\frac{6 \mathrm{ft}}{20 \% \text { man way }}$ Flexible Containment Bag Used: Yes $1 \mathrm{NO}$

Other: Connected Sft and $8 f_{t}$ sections - welded

Observations:

Range/Range of Motion: At $6 f_{t}$ height able to reach horizontally $\sim 8 \mathrm{ft}$ circle

Ease of Handling/Maneuverabilitty: Rela tively easy to move around manway. Less /iffing

Retrieval efficiency: Able to maintain constant contact with material; $\sim 11 / 2-2$ cuyds, Flow/Vacuum Control: $12-16$ in vacuum; breater relief often

Ease of section changeout/addition: NA

Hoist operation: Onhy used to hold hose. No change in height reguired.

Camera viewing: NA

Safety: No additional issues.

Working Platform: No additionol issues.

Containment: No addivional issues.

other: Worked better than long section connected by hose Soil was shoueled to end of vessel so more loose than during tests yesterday. Scueral plugs occurred in hose scetion( $\left(6^{\prime \prime} /\right.$ line $)$

Operator: Tim Huey Observers: Steve Birrer Mike Griftin Shawn Doolittle 


\section{Silo 3 Vacuum Wand Demonstration Test Data Sheet}

Page 1 of 2

Run No.: RTL-1-EEE Run Date: $4-23-03$

Time Run Initiated: $8: 40 \quad$ Time Run Completed: $9: 10$

Equipment Tested:

Vacuum Wand: $3^{\prime \prime} \times / 3 \mathrm{ft}$ Hose Size: $3^{\prime \prime}$ Nozzle Type: Round

Dome Height above Surrogate: $\frac{6 \mathrm{ft}}{20 \% \text { man way }}$ Flexible Containment Bag Used: Yes 1 No

Other: Connected S ft and $8 f_{t}$ sections - welded

Observations:

Range/Range of Motion: At $6 \mathrm{ft}$ height able to reach horizontally $\sim 8 \mathrm{ft}$ circle

Ease of Handling/Maneuverabililty: Rela fively easy to move around manway. Less/iffing

Retrieval efficiency: Able to maintain constant contact with material; $\sim 11 / 2-2$ cuyds,

Flow/Vacuum Control: $12-16$ in vacuum; breater relief often

Ease of section changeout/addition: NA

Hoist operation: Onhy used to hold hose. No change in height reguired.

Camera viewing: NA

Safety: No additional issues.

Working Platform: No additional issues.

Containment: No addivional issues.

Other: Worked better than long section connected by hose Soil was shoveled to end of vessel so more loose than during tests yesterday. Scueral plugs occurred in hose section(. "6" Iine)

Operator: Tim Huey Observers: Steve Birrer Mike Griftin Shawn Doolitile 


\section{Silo 3 Vacuum Wand Demonstration Test Data Sheet Page 2 of 2

$$
\text { RTL-FEEE }
$$

Other Notes / Observations:

Pugs rypically occurring ax bends in the 5" and 6" hose sections. Problem is not enough air at nozzle. Need additional holes in wand? larger holes.

May need air bleeds at operator end.

Cradle needs to have rollers so hose can be pulled through easier. Petrieval rate appeared visually to bo faster than during
Yesterdays test, however, line plugs caused dountime with overall result of same retrieval rate. Need to raise pulley height to $\tilde{\text { (minimum) }}$ ) above the manway.

Operator:

Observers: 


\section{Silo 3 Vacuum Wand Demonstration Test Data Sheet}

\section{Page 1 of $\underline{2}$}

Run No.: RTL-1-NNN Run Date: $4-23-03$

Time Run Initiated: 9:36 Time Run Completed: 9:56

Equipment Tested:

Vacuum Wand: 4 4"x/3ft Hose Size: 4 4" Nozzle Type: Round

Dome Height above Surrogate: $\frac{B}{2+}$ Flexible Containment Bag Used: Yes / No

Other: Sft and $8 \mathrm{ft}$ secrions welded rogether

Observations:

Range/Range of Motion: Acceptable; little mone difficult than $3^{\prime \prime}$

Ease of Handling/Maneuverabililty: Acetptable.

Retrieval efficiency: Able to maintain contact with material. Filled hopper in 20 minutes

Flow/Vacuum Control: 15 in vacuum.; fairly strady j som breater relief still

Ease of section changeout/addition: $N A$

Hoist operation: Onty used to hold hose. No change in height reguired.

Camera viewing: $N A$

Safety: No additional issurs.

Working Platform: No additional issues

Containment: No additional issues.

Other: Retricual rate $\sim 41 / 2$ yds $/ \mathrm{hr}$

Operator: Tim Huey

Observers: Strve Birrer Mike Griffin Nat Politi 


\section{Silo 3 Vacuum Wand Demonstration Test Data Sheet Page 2 of 2}

Other Notes / Observations: Switched to $20 "$ manway to give more height from material
and ability to move the wand around.

moved hoses around to miminize bands. No plugs oceurred.

Use of long wobes is definately easier and more productive than using hose.

Still need a little more air blerd. Put bleed in end of hose.

Will want multiple hose and wand devices so can work multiple manways w/o having to move equipment around.

Need sterving wheel handles on tubes. Removable

Make rubes in 4 and 8 foot lengths Camloct connections?

Minimize bends in final design. Use hose and not piping.
(clear)

Operator:

Observers: 